\title{
Novel Devices for Individualized Controlled InHalation Can Optimize Aerosol Therapy in Efficacy, Patient Care and Power of Clinical Trials
}

\author{
A. Fischer ${ }^{1}$, J. Stegemann ${ }^{1}$, G. Scheuch ${ }^{1}$, R. Siekmeier ${ }^{2}$ \\ ${ }^{1}$ Activaero GmbH, Gemünden, Germany; ${ }^{2}$ Federal Institute for Drugs and Medical Devices (BfArM), Bonn, Germany
}

\begin{abstract}
In the treatment of pulmonary diseases the inhalation of aerosols plays a key role - it is the preferred route of drug delivery in asthma, chronic obstructive pulmonary disease (COPD) and cystic fibrosis. But, in contrast to oral and intravenous administration drug delivery to the lungs is controlled by additional parameters. Beside its pharmacology the active agent is furthermore determined by its aerosol characteristics as particle diameter, particle density, hygroscopicity and electrical charge. The patient related factors like age and stage of pulmonary disease will be additionally affected by the individual breathing pattern and morphometry of the lower airways. A number of these parameters with essential impact on the pulmonary drug deposition can be influenced by the performance of the inhalation system. Therefore, the optimization of nebulisation technology was a major part of aerosol science in the last decade. At this time the control of inspiration volume and air flow as well as the administration of a defined aerosol bolus was in the main focus. Up to date a more efficient and a more targeted pulmonary drug deposition - e.g., in the alveoli - will be provided by novel devices which also allow shorter treatment times and a better reproducibility of the administered lung doses. By such means of precise dosing and drug targeting the efficacy of inhalation therapy can be upgraded, e.g., the continuous inhalation of budesonide in asthma. From a patients' perspective an optimized inhalation manoeuvre means less side effects, e.g., in cystic fibrosis therapy the reduced oropharyngeal tobramycin exposure causes fewer bronchial irritations. Respecting to shorter treatment times also, this result in an improved quality of life and compliance. For clinical trials the scaling down of dose variability in combination with enhanced pulmonary deposition reduces the number of patients to be included and the requirement of pharmaceutical compounds. This review summarises principles and advances of individualised controlled inhalation (ICI) as offered by the AKITA ${ }^{\circledR}$ inhalation system.
\end{abstract}

This article is dedicated to Dr. W. Stahlhofen, former head of the GSF - German Research Center for Environmental Health, Frankfurt/Main, Germany at the occasion of his $80^{\text {th }}$ birthday.
Key words: aerosol, inhalation therapy, pulmonary drug delivery, liquid nebulizer

\section{INTRODUCTION}

The lung is one of the largest human organs standing in close contact to the environment. Therefore, it is at risk for diseases caused by environmental factors like dusts, smoke and bacteria. As a consequence, a number of mechanisms have been developed in the evolutionary process to minimise the risk for pulmonary diseases. Among others the most effective means are anatomic barriers, cough, mucociliary apparatus, airway epithelium, secretory immunoglobulin A $(\operatorname{IgA})$, dendritic cell network and lymphoid structure [1]. For example, about $90 \%$ of inhaled particles with diameters larger than 2-3 $\mu \mathrm{m}$ are deposited in the central airways on the mucus overlying the cilial epithelium $[1,2$, 3]. After deposition they are rapidly transported to the trachea by means of the mucociliary escalator and swallowed into the gastrointestinal tract. Furthermore, the thickness of mucus layer and respiratory epithelium impacts the absorption of biomolecules deposited in the central airways [4].

Because of the high number of pulmonary diseases and the obviously easy way for drug delivery to the lungs a large number of clinical trials were performed to examine the therapy options with aerosols. Many types of inhalers were developed and since about 30 years hand-held devices (metered dose inhalers (MDI) and dry powder inhalers (DPI)) for inhalant treatment of asthma and chronic obstructive pulmonary disease (COPD) are available [4, 5, 6].

However, due to needs of dosing, galenics and special patient requirements electronic inhalation systems for the nebulization of liquid drug solutions are still important today. For example, the high dose requirements for inhalant antibiotics and iloprost in the treatment of cystic fibrosis and pulmonary hypertension make the use of electronic liquid nebulizers essential [7]. For another important drug, DNAse for the antiinflammatory therapy in cystic fibrosis, the inhalation with MDIs and DPIs is not available because of non feasible galenics. Also for young children which are not in the position to coordinate the right breathing manoeuvre with MDIs and DPIs liquid nebulization systems are necessary [8]. The older models of such devices are driven by ultrasonic and venturi technolo- 
gy with the handicaps of poor effectiveness in pulmonary drug deposition and long treatment times. Especially a reduction of the treatment times became available with the new vibrating mesh technology which also allows now to build portable battery operated hand-held devices.

Another important field of inhalant therapy is treatment of systemic diseases by means of aerosols [4, 5 , $6,9,10,11,12,13]$. The latter is encouraged by the enormous size of the alveolar surface which is in average about the half of a tennis court $\left(132 \mathrm{~m}^{2}\right)[4,6,12$, 13]. Further favourable terms are the low thickness of the alveolar epithelium, mostly between 0.1 and 0.2 $\mu \mathrm{m}[4,10,14]$, the high perfusion of the lung with a blood volume of about $5 \mathrm{l} / \mathrm{min}$ at rest [15] and the missing of hepatic first pass effect for administered drugs and other mechanisms, as macrophage uptake, inhibiting the absorption of biomolecules $[6,9,13,14$, 16, 17]. However, even though there were early attempts for such type of therapy, e.g., the first studies for insulin inhalation for treatment of diabetes mellitus in 1924 and 1925 [11, 18, 19, 20], the inhalant therapy of systemic diseases is not yet established in clinical routine $[6,9,11,15,16]$. In the future, however, a number of promising approaches can be expected, e.g., inhalant heparin against venous thrombosis [21, 22].

Both, inhalant treatment of lung diseases as well as inhalant treatment of systemic diseases requires administration of sufficient and reproducible drug doses in distinct lung regions (central vs. peripheral) in a convenient manner to ensure pulmonary diseases. The deposition behaviour of aerosol particles in the respiratory tract depends on a number of physical (properties of the particle), chemical (e.g., properties of the drug) and physiological (e.g., breathing pattern, pulmonary diseases) factors $[2,3]$. If these are not considered adequately, it is not possible to deposit a sufficient and reproducible amount of a drug in a predefined lung region (e.g., bronchi or alveoli) by pulmonary administration. The low efficiency of commercially available inhalation systems and the large variability of the administered lung doses were the major problems that prevented this administration route for so many years. However, since about 20 years there was a strong progress in aerosol research and pulmonary drug delivery.

Actually an individualized controlled inhalation (ICI) technology is the most promising novel approach for improvement of pulmonary aerosol deposition $[3,23]$. In our review we briefly describe the advantages of such a type of a breathing manoeuvre in research and clinical treatment focusing on the AKITA ${ }^{\circledR}$ inhalation device for liquid nebulization.

\section{General Problems of Inhalation THERAPY}

In general, problems in inhalation therapy can be caused by the pharmaceutical compound, the used nebulizer or the patient to be treated. In consequence, depending on the underlying cause several approaches exist for optimisation of the therapy. For example, the pharmaceutical compound can be subject of rapid inactivation within the nebulization process (e.g., by aggregation and oxidation) or after pulmonary deposition (e.g., by proteolytic cleavage) or may be too large to penetrate the alveolar membrane which is a prerequisite for treatment of systemic diseases by means of aerosols $[4,5,6,9]$. Substance related problems can be solved, e.g., by addition of stabilizers, proteinase inhibitors as well as absorption enhancers $[4,6]$. If the problem is caused by the analyzer, e.g., by a low aerosol output, an inadequate aerosol distribution width or a too high variability of the aerosol particle spectrum it can be solved by use of another nebulizer type (e.g., MDI, ultrasonic nebulizer). Finally, if the patient itself causes the problem (e.g., lung function, pulmonary morphometry, breathing technique and compliance) an improvement can be achieved by the use of another nebulizer and an optimization of the breathing manoeuvre $[2,3,6]$. However, it should be noted that different problems often occur together and in consequence their optimal solution has to consider all underlying aspects. The principle problems and their solutions are briefly compiled in Table 1 (see Table 1).

Table 1. Problems in aerosol therapy and their solution (modified according to $[4,6,13,24]$ ).

\begin{tabular}{l|l|l}
\hline Source of the problem & Type of the problem & Solution of the problem \\
\hline Device & $\begin{array}{l}\text { Low aerosol output } \\
\text { Aerosol distribution width } \\
\text { Variability of aerosol particle spectrum } \\
\text { Long treatment times for drug solutions }\end{array}$ & $\begin{array}{l}\text { Vibrating mesh nebulizers } \\
\text { Dry powder inhalers (DPI) } \\
\text { Metered dose inhalers (MDI) } \\
\text { Vibrating mesh nebulizers }\end{array}$ \\
\hline Compound & $\begin{array}{l}\text { Formulation: } \\
\text { Chemical / physical stability } \\
\text { Aerodynamic diameter } \\
\text { Adhesion force } \\
\text { Electrical charge }\end{array}$ & $\begin{array}{l}\text { Optimisation of manufacturing: } \\
\text { Refinement of production processes } \\
\text { Addition of stabilising excipients }\end{array}$ \\
& $\begin{array}{l}\text { Biology: } \\
\text { Permeability } \\
\text { Metabolism }\end{array}$ & $\begin{array}{l}\text { Improvement of galenics: } \\
\text { Addition of absorption enhancers and } \\
\text { proteinase inhibitors and packing into } \\
\text { particles }\end{array}$ \\
& Immunogenicity & \\
& & \\
\hline
\end{tabular}




\section{Novel Devices to Enhance Pulmonary Delivery}

Many existing inhalation devices are based on the bolus inhalation technique $[3,25]$. For example, MDIs and DPIs are supposed to deliver the aerosol cloud at the beginning of a breath. This leads to a more efficient lung deposition than an inhalation of an aerosol over the entire inspiration because the clean air that follows the aerosol cloud transports the particles deeply into the lungs and extends their pulmonary residence time $[2,3]$. Another commercially available system, the AERx ${ }^{\circledR}$ Pulmonary Drug Delivery System of Aradigm (USA) uses a bolus of aerosol particles that can be activated during a certain time point during an inspiration. The bolus is produced by a piston that empties a small liquid reservoir into the inhalation air. Other devices, like the AKITA ${ }^{\circledR}$ Inhalation System (Activaero, Germany; Fig. 1) and the I-neb ${ }^{\circledR}$ AAD $^{\circledR}$ System (Philips-Respironics, Netherlands) use liquid nebulizer systems which are operated only at a certain time during an inhalation cycle and therefore also use the bolus inhalation technique to increase particle deposition in the lung [3].

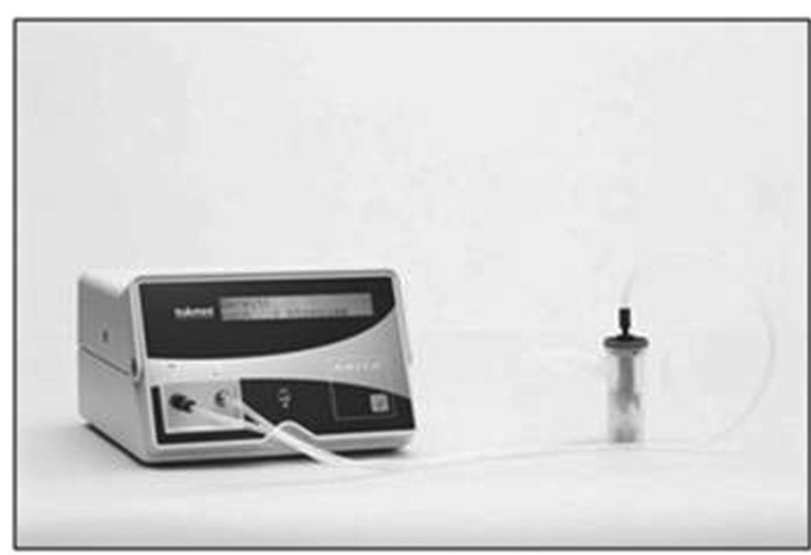

Fig. 1. AKITA ${ }^{\circledR}$ technology with Pari LC Star nebulizer.

Currently, the AKITA ${ }^{\circledR}$ technology is the most advanced aerosol delivery technology as it is the only one that actively controls the entire inhalation manoeuvre of the patient. This is done by means of a positive air pressure delivered by a computer controlled compressor which is programmed on base of the patient's individual lung function data. By Activaero's SmartCard technology the lung function data can be submitted

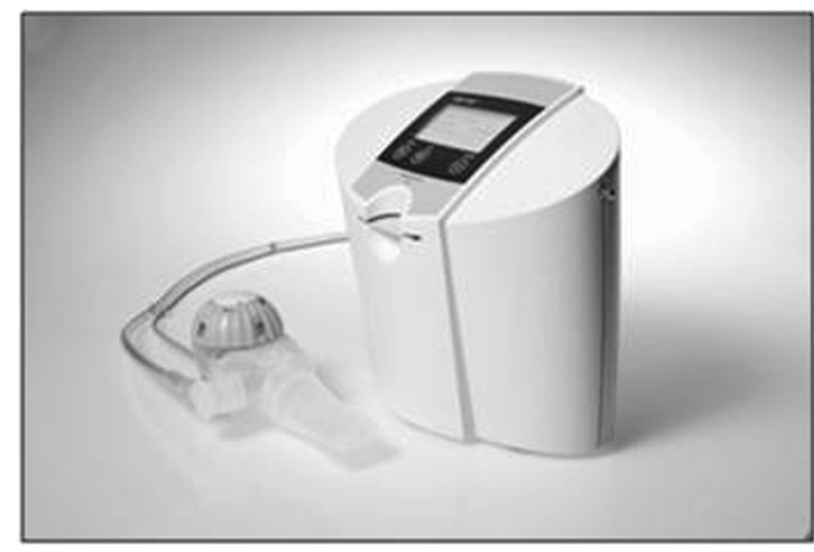

Fig. 2. AKITA ${ }^{\circledR 2}$ system with PARI APIXNEB nebulizer.

quickly after a prior lung function test to the AKITA ${ }^{\circledR}$ device. The next generation of this technology, AKITA ${ }^{\circledR} 2$, is operating with ultrasonic and ultrasonic mesh nebulizers. In Fig. 2 the latest version is shown together with the APIXNEB ${ }^{\circledR}$ nebulizer that uses PARI vibrating mesh technology (see Fig. 2). This new nebulizer is able to nebulize up to $99 \%$ of the filled dose into particles with mass median aerodynamic diameter (MMAD) $<4 \mu \mathrm{m}-$ measured for $0.9 \% \mathrm{NaCl}$-solution.

\section{Advantages OF INDIVIDUALISED CONTROLLED INHALATION FOR RESEARCH AND ROUTINE THERAPY}

The optimisation of the breathing manoeuvre by individualized controlled inhalation (ICI) has a number of advantages for clinical trials with pulmonary drug administration and in the clinical routine of hospital and outpatient treatment (see Table 2).

In clinical trials, the needed number of patients to confirm an effect depends on the level of significance $(\alpha)$, the statistical power $(1-\beta)$, the estimated difference, and the estimated standard deviation. The higher is the number of cases, the lower are the significance and the statistical power $(1-\beta)$. It is noteworthy that the relations between these parameters and the number of cases are non-linear and can be calculated. The reduction of dose variability by means of ICI is significant. A cross-over study with inhaled tobramycin was performed in healthy volunteers [26], where the subjects used a conventional jet nebulizer system (PARI Turbo BOY with LC Plus ${ }^{\circledR}$ ) and an AKITA ${ }^{\circledR}$ system (AKITA

Table 2. Advantages of individualised controlled inhalation (ICI) for research and routine therapy.

\begin{tabular}{l|l|l}
\hline Advantages of ICI & Benefit for clinical trials & Benefit for out patient treatment \\
\hline Reduction of side effects & Lower number of drop outs & Higher quality of life and compliance \\
\hline Lower lung drug dose variability & Reduction in the number of patients to be included & Increase of efficiency \\
\hline Better drug targeting & \multicolumn{2}{|c}{ Increase of efficiency } \\
\hline Electronic compliance control & Reduction in the number of patients to be included & Extended feedback for physicians \\
\hline Higher drug exploitation & \multicolumn{2}{c}{ Lower drug costs } \\
\hline
\end{tabular}




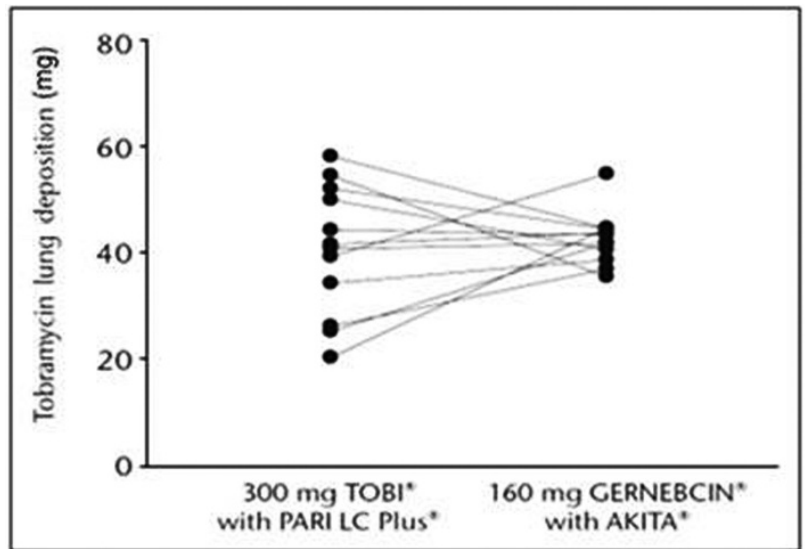

Fig. 3. Tobramycin lung deposition after inhalation by means of a conventional jet nebulizer system (PARI Turbo BOY with LC Plus ${ }^{\circledR}$ ) and an AKITA ${ }^{\circledR}$ system (AKITA I compressor with PARI LC Star $\left.{ }^{\circledR}\right)$.

I compressor with PARI LC Star $\left.{ }^{\circledR}\right)$. With the conventional jet nebulizer system the achieved average lung deposition in total was $40.78 \mathrm{mg}$ and in the AKITA ${ }^{\circledR}$ group $42.81 \mathrm{mg}$. The lung dose measured by means of gamma scintigraphy showed no statistical difference. But with $\pm 12 \mathrm{mg}$ vs. $\pm 5 \mathrm{mg}$ the variation of the tobramycin lung dose was significantly higher $(\mathrm{P}=0.06)$. For the study group with the conventional nebulizer system this means $30 \%$ variation related to the total lung dose, while in the AKITA $^{\circledR}$-group this was just $11 \%$ (see Fig. 3). This example demonstrates the potential of inhalation systems with ICI technology to reduce the number of patients in clinical trials, respectively to increase the chance of proofing efficiency.

An optimized inhalation manoeuvre results in a more precise drug targeting, which also helps to avoid undesired side effects. For example this aspect can be addressed to the inhalant treatment in cystic fibrosis where oropharyngeal tobramycin exposure can cause irritations to the patients. The comparison of gamma scintigraphy imaging after tobramycin inhalation with and without ICI technology [26] is also well appropriated to show the differences of the deposition (see Fig. 4). With conventional nebulizers the same tobramycin lung dose only can be achieved with almost the double of fill in dose (300 mg vs. $160 \mathrm{mg}$ ) and with a strikingly higher oropharyngeal loading of tobramycin (see Fig. 4b).
From the perspective of an investigator of clinical trials the use of ICI technology can reduce the risk of drop outs because of side effects. Also the saving of drug costs can be considerable. In the study of Brand et al. the AKITA ${ }^{\circledR}$ system allows to achieve the equivalent lung dose but by saving $140 \mathrm{mg}$ tobramycin per treatment. In Europe $1 \mathrm{mg}$ of tobramycin actually costs about 20 cent (calculation on base of pharmacy sales price for TOBI ${ }^{\circledR}$ in Germany September 2009; source http://www.pharmazie.com/). A standard therapy in cystic fibrosis requires an inhalation twice daily for a longer time period - here the AKITA ${ }^{\circledR}$-System can save about $56 €$ per patient and treatment day (140 mg saving per treatment x $0,20 € / \mathrm{mg} \times 2$ treatments per day $=56 €$ ).

A further advantage which came up with ICI technology is therapy control. While still no conventional liquid nebulizer is available with features for scanning information about the nebulized drug dose, treatment time, etc.; systems like AKITA ${ }^{\circledR}$ can provide that. This is most relevant in longer studies with longer outpatient treatment as actually started for antibiotic inhalation in patients with bronchiectasis and severe COPD with up to 1 year treatment time. If very precise data about the patient compliance are available an efficiency of the drug can not be covered by undetected insufficient compliance.

In consequence, these advantages opened by ICI technology also will provide a positive impact on routine care (in-hospital and outpatient) whereat better clinical effects and lower side effects are most important. In the result this improves the patient's quality of life which is especially important in pulmonary diseases where inhalation has to follow as a permanent treatment over months and years (e.g., patients with COPD and cystic fibrosis). Additionally, the means of compliance control as offered by the AKITA ${ }^{\circledR}$ or the I-neb ${ }^{\circledR}$ AAD $^{\circledR}$ system allows the physician to have more control on the therapy. This has been shown for cystic fibrosis patients [27], which were pseudomonas positive for the first time and had to start an antibiotic eradication therapy by 3 months of inhalation with colistin. In patients where eradication failed the compliance data, provided by an I-neb ${ }^{\circledR}$ AAD $^{\circledR}$ system, help to make decisions about the further strategy in treatment. While patients with compliance over 80\% were shifted to another antibiotic patients with insufficient compliance were included in an inhalation training program guided by trained physiotherapists.
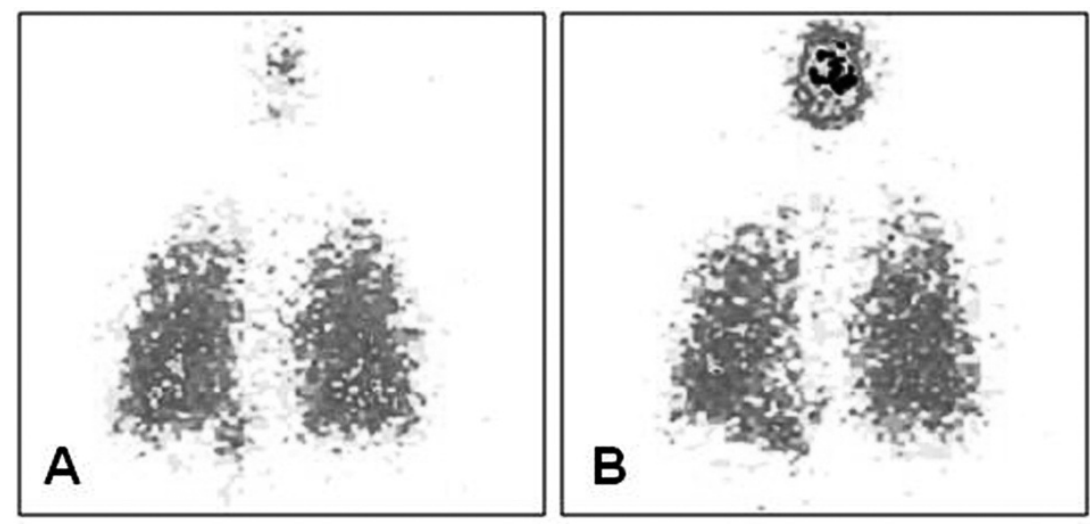

Fig. 4. Tobramycin detection by gamma camera in one of the study patients. A Lung deposition of $37.2 \mathrm{mg}$ tobramycin after inhalation of $160 \mathrm{mg}$ Gernebcin ${ }^{\circledR}$ by means of the AKITA ${ }^{\circledR} ; \mathrm{B}$ - Lung deposition of $26.4 \mathrm{mg}$ tobramycin after inhalation of $300 \mathrm{mg}$ TOBI ${ }^{\circledR}$ by means of Pari LC Plus ${ }^{\circledR}$. 
Finally, pharmaceutical-economical aspects are also important. In most cases ICI technology can halve the required fill in dose or even more [28]. For the treatment of pulmonary hypertension or cystic fibrosis where expensive drugs are easily raising up costs of more than $20000 €$ per patient and year this opens the potential for enormous drug cost savings.

\section{StUdy Data Demonstrating THE IMPROVEMENT OF PULMONARY DRUG Deposition BY INDIVIDUALISED CONTROLLED INHALATION}

A study performed by Dopfer et al. in patients with cystic fibrosis examined the antibiotic inhalation with tobramycin (16 patients; age $21.8 \pm 7.1$ years, range 13 39 years, FEV1 $61 \%$ of predicted values, range $36-116 \%$ ) [28]. In a cross-over design the patients received inhalant tobramycin twice daily compared to the clinical routine. The reference medication was TOBI ${ }^{\circledR}$ as approved for the treatment for chronic pseudomonas infection in cystic fibrosis patients. The fill in dose with TOBI ${ }^{\circledR}$ was $300 \mathrm{mg}$ tobramycin in 5 $\mathrm{ml}$ which was shown to be effective in two pivotal trials [29] using the conventional inhalation system PARI LC Plus ${ }^{\circledR}$ with a PARI Boy $\mathrm{N}^{\circledR}$ compressor. From early studies it was known that such nebulizers with venturi technology cannot deliver more than $10-15 \%$ of the fill in dose into the lungs. As a reference for the lung deposition of tobramycin the blood serum levels can be measured, which was in the median $0.95 \mathrm{mg} / 1$ (range from not measurable up to $3.62 \mathrm{mg} / \mathrm{l}$ ) when measured in the original TOBI ${ }^{\circledR}$ trials with 520 cystic fibrosis patients (mean age 21 years) [29]. In the present study tobramycin was inhaled at three different days and tobramycin serum concentrations were determined at all study days 1 hour after start of the first administration in the morning. After a wash out period of three days all patients were shifted to the inhalation with the AKITA ${ }^{\circledR}$ system combined with a PARI LC Plus ${ }^{\circledR}$ nebulizer. The controlled inhalation with AKI$\mathrm{TA}^{\circledR}$ makes it possible to calculate the fill in dose which is necessary to achieve the desired lung deposition dose. To fit the reference inhalation with TOBI $^{\circledR} /$ LC Plus $^{\circledR}$ the fill in dose for AKITA ${ }^{\circledR}$ was calculated to be $150 \mathrm{mg}$ tobramycin - with the $\mathrm{TOBI}^{\circledR}$ product this means $2.5 \mathrm{ml}$ fill in volume. The results show that there were no differences in tobramycin serum concentrations among the three study days in both methods (controlled inhalation: $0.983 \pm 0.381$ $\mathrm{mg} / \mathrm{l}, 1.119 \pm 0.448 \mathrm{mg} / \mathrm{l}$ and $1.194 \pm 0.568 \mathrm{mg} / \mathrm{l}$; conventional inhalation: $1.075 \pm 0.798 \mathrm{mg} / 1,1.294 \pm$ $0.839 \mathrm{mg} / 1$ and $1.269 \pm 0.767 \mathrm{mg} / \mathrm{l}$; means $\pm \mathrm{SD}$ on days 1,2 and 3 , respectively). Even though the drug amount was double in the conventional technique, there was no significant difference in its overall serum concentration from the three study days (conventional inhalation: $1.210 \pm 0.783 \mathrm{mg} / \mathrm{l}$, controlled inhalation: $1.092 \pm 0.461 \mathrm{mg} / \mathrm{l})$. But moreover the AKITA ${ }^{\circledR}$ system was not only in the position to achieve the same tobramycin lung dose with half of the fill in dose. The further data analysis demonstrates that ICI technology can provide an improved reproducibility of drug delivery to the lungs - the coefficient of variation was $42 \%$ for AKITA ${ }^{\circledR}$ in contrast to $65 \%$ for conventional inhalation. From the patients perspective the most relevant result was that the AKITA ${ }^{\circledR}$ system save them 12 min inhalation time per treatment -7.8 min with AKITA versus $20 \mathrm{~min}$ with the conventional nebulizer. In the outpatient routine with a two time daily inhalation this makes almost 25 min per day and almost 3 hours per week. In summary this study proves the potential of ICI technology to reduce the required drug dose, the treatment time for the patient and at the same time a much better reproducibility of the desired lung dose.

The findings from the study of Dopfer et al. in cystic fibrosis patients were confirmed by investigations from Brand et al. which were already discussed before in the connection with ICI technology and its benefit for clinical trials [26]. In contrast to Dopfer et al., Brand et al. compared the performance between AKI$\mathrm{TA}^{\circledR}$ and a conventional nebulizer with a study group of adult healthy volunteers. As healthy volunteers are a much more homogeneous collective than a cohort of cystic fibrosis patients (range in FEV1 from 36-116\% of predicted values in the study of Dopfer et al. [28]) differences in the device performance can be regarded more properly. This study also follows a cross-over design, where each subject has to perform inhalation of tobramycin with a conventional nebulizer and the AKITA $^{\circledR}$ system. Again the primary criteria was bioequivalence of tobramycin in lung deposition with the reference combination TOBI ${ }^{\circledR} 300 \mathrm{mg} /$ PARI TurboBoy $N^{\circledR}$ compressor and the PARI LC Plus ${ }^{\circledR}$ nebulizer. The AKITA ${ }^{\circledR}$ system was equipped with a PARI LC Star nebulizer and the fill in dose was $160 \mathrm{mg}$ tobramycin in $4 \mathrm{ml}$ of volume (Gernebcin ${ }^{\circledR} 80 \mathrm{mg} / 2 \mathrm{ml}$ - a registered compound for inhalation in Germany). In addition to measurements of tobramycin serum concentration 1 hour after inhalation the total tobramycin lung deposition was detected for each subject by means of gamma scintigraphy. The lung deposition that was reached averaged $42.81 \pm 4.93 \mathrm{mg}$ and $40.78 \pm 12.21 \mathrm{mg}$ with Gernebcin ${ }^{\circledR} / \mathrm{AKITA}^{\circledR}$ and $\mathrm{TOBI}^{\circledR} / \mathrm{LC}$ Plus ${ }^{\circledR}$, respectively (means $\pm \mathrm{SD}, \mathrm{P}=0.06$ ). However, the tobramycin lung deposition/dosage was higher for Gernebcin ${ }^{\circledR} /$ AKITA $^{\circledR}$ than for TOBI ${ }^{\circledR} /$ Pari LC Plus ${ }^{\circledR}(26.8 \pm 3.1 \%$ vs. $13.6 \pm 4.3 \%)$ reflecting the lower extrapulmonary deposition in the upper respiratory tract (see Fig. 3). Correspondingly, the variation in the lung dosage of the subjects was lower for Gernebcin ${ }^{\circledR} /$ AKITA $^{\circledR}$ than for TOBI ${ }^{\circledR} /$ Pari LC Plus ${ }^{\circledR}$ (+5 mg vs. $\left.+12 \mathrm{mg}\right)$. Measurement of tobramycin serum concentration provides further information on pulmonary drug deposition and absorption. Serum concentrations of tobramycin determined 1 hour after the inhalation were $0.56 \pm 0.19 \mathrm{mg} / \mathrm{l}$ and $0.39 \pm 0.21 \mathrm{mg} / 1$ after nebulization of $160 \mathrm{mg} /$ Gernebcin $^{\circledR} /$ AKITA $^{\circledR}$ and $300 \mathrm{mg}$ TOBI $^{\circledR} /$ Pari LC Plus ${ }^{\circledR}$, respectively.

The results confirm the advantages of ICI technology in efficiency and precision of drug delivery to the lungs over conventional nebulizers. By using the AKI$\mathrm{TA}^{\circledR}{ }^{\circledR}$ system the required fill in dose was reduced to $53 \%$ of the original $\mathrm{TOBI}^{\circledR}$ dose - under outpatient treatment conditions the daily cost savings would be around $56 €$ (according to the calculation described before). Evidence for bioequivalence for the lung de- 
position of tobramycin is powerful as it has been shown directly by gamma scintigraphy and not only indirectly by serum level measurements. The gamma scintigraphy results demonstrate convincingly the much more precise drug dosing of ICI technology the variability of the total tobramycin lung deposition was sized down over 58\% - from $12 \mathrm{mg}$ to $5 \mathrm{mg}$. This improvement is significantly higher than found in the study of Dopfer et al., because in this study the homogeneous group of healthy volunteers was much better appropriated to demonstrate a device related effect than a patient collective.

Köhler et al. also studied pulmonary deposition with AKITA ${ }^{\circledR}$ 's ICI technology in comparison to conventional inhalation [30]. The investigators also analysed the convenience of the patients with the novel inhalation method by means of a questionnaire (see below). Their study was performed in 13 cystic fibrosis patients aged $14 \pm 4$ years (means $\pm S D$; 8-20 years). Patients inhaled sodium chromoglycate (SCG) by means of a breath controlled inhalation (AKITA ${ }^{\circledR}$ + PARI LC Star ${ }^{\circledR}$ nebulizer) and a conventional inhalation (Parimaster ${ }^{\circledR}+$ PARI LC Star ${ }^{\circledR}$ nebulizer, manual interruptor). SCG served as a marker substance for pulmonary drug deposition and its concentration was measured in urine for calculation of pharmacokinetics for up to 12 hours after inhalation. The total amounts of SCG excreted in the urine were higher after individualised controlled inhalation than after conventional inhalation $(2.22 \pm 0.61 \mathrm{mg}$ vs. $1.63 \pm$ $0.59 \mathrm{mg}, \mathrm{P}<0.001)$. Thus, on average, the amount of drug deposited in the lung was $46 \%$ higher after administration by means of the novel technique. In addition, the calculated absorption half-life times of SCG were significantly shorter after individualised controlled breathing than after conventional inhalation (78 \pm 23 min vs. $107 \pm 29 \mathrm{~min}, \mathrm{P}=0.006$ ) suggesting a more peripheral deposition (i.e., in the alveolar region) by means of the novel technique. Again, the required inhalation times were significantly shorter for the inhalation controlled by ICI technology breathing than for the conventional inhalation $(6.6 \pm 0.9 \mathrm{~min}$ vs. 8.7 $\pm 2.4 \mathrm{~min}, \mathrm{P}=0.007)$. In summary, controlled inhalation allows an improved pulmonary deposition combined with a reduction of inhalation time [30].

\section{EFFECT OF Individualised Controlled Breathing on PATIEnt Convenience}

The success of an inhalation therapy, especially in patients treated repeatedly or for longer time periods, strongly depends on patient convenience and compliance with the prescribed treatment scheme. Up to now only two studies investigating the convenience with the AKITA ${ }^{\circledR}$ system for controlled breathing were performed [30, 31]. As described above, Köhler et al. studied pulmonary deposition of SCG and convenience of individualised controlled breathing in $13 \mathrm{pa}-$ tients with cystic fibrosis. Patients were asked to quantify their general impression of the AKITA $^{\circledR}$ device (ranging between very good and very poor), to assess the speed of the inhalation by means of the AKITA ${ }^{\circledR}$ and to assess the time of inhalation for one breath using the AKITA ${ }^{\circledR}$ system. All questions had to be an- swered by indicating a cross on a scale ranging from 0 to 10 . In summary, an assessment of 'good to very good' for the inhalation was given from 12 out of 13 patients $(92 \%), 11$ patients $(85 \%)$ considered the flow rate of $200 \mathrm{ml} / \mathrm{s}$ neither too high nor too low and 9 patients $(69.2 \%)$ considered the time of inspiration neither too short nor too long [30]. In the other study from Fischer and Schiefer patient convenience was investigated in a subgroup of 10 out of 72 patients with cystic fibrosis [31]. The patients included in the subgroup continued inhalation with the AKITA $^{\circledR}$ device after completion of another study and answered a detailed questionnaire on the satisfaction with this system. At the time of answering the questionnaire the patients had an experience of in average 5.5 months (3-6 months). The patients inhaled up to 4 different drugs with the device. Five patients mentioned that they continued the use of their old device, e.g., on travel. Overall satisfaction was rated with 'Extremely satisfied' (7 patients) or 'Very satisfied' (3). The controlled inspiration was assessed 'Very positive' (8) or 'Get along well most of the time' (2). Average importance/satisfaction ratings (max. 5) for selected aspects were: 'Reliable dosage' (4.4/4.4), 'Reduced inhalation times' (3.9/4.4) and 'Transport' (3.8/2.5). The treatment times assessed by the patients were significantly shorter if the AKITA ${ }^{\circledR}$ device was used $\left(\right.$ AKITA ${ }^{\circledR}$ vs. former nebulizer (mostly PARI Master): $24.0 \mathrm{~min}$ vs. $41.5 \mathrm{~min},-42 \%)$. However, even though patients appreciate shorter inhalations due to the high efficiency of the system the benefit of time saving is not rated as most important. More important was the reliability of dosage that was ensured by individualised controlled inhalation.

\section{CONCLUSIONS}

In the last decades there was a large increase of the understanding of aerosol physics and mechanisms of pulmonary aerosol deposition. Both have been followed by an improvement of aerosol therapy in respect to efficiency, cost effectiveness and patient convenience. However, the novel ICI technology which applies the findings of modern aerosol physics and therapy allows a further optimisation of inhalation therapy. It is largely based on the results of individual lung function which plays a central role in inhalation therapy. It is suggested that in the future aerosol therapy will not be, as it was in the past, a type of standard therapy with fixed application volumes and times, but a type of therapy which is depending on the patient's anthropometric data and lung function. Optimization of the pulmonary aerosol deposition serves as a prerequisite for the further extension of aerosol therapy, e.g., inhalation of pharmaceuticals for local (e.g., tobramycin in cystic fibrosis patients) and systemic (e.g., insulin in diabetes mellitus) therapy. And finally ICI technology at the first time allows a precise targeting of the drug to specified lung region, e.g., a high alveolar deposition of $\alpha_{1}$-antitrypsin in the therapy of $\alpha_{1}$-antitrypsin deficiency. With this new tool a number of long-time established aerosol therapies can be optimized in the future. 
Conflicts of interest: Dr. Rüdiger Siekmeier has no conflicts of interest in relation to this article. Dr. Gerhard Scheuch is $\mathrm{CEO}$ of the Activero GmbH Gemünden and Mr. Fischer and Mr. Stegemann are employed by Activero. Dr. Scheuch is a consultant for several pharmaceutical companies in the field of aerosol medicine and pulmonary drug delivery (e. g., Bayer-Schering, Boehringer/Ingelheim, GSK, Novartis, Talecris, Sandoz).

\section{REFERENCES}

[1] Nicod LP. Pulmonary defence mechanisms. Respiration 1999; 66: 2-11.

[2] Scheuch G, Kohlhaeufl MJ, Brand P, Siekmeier R. Clinical perspectives on pulmonary systemic and macromolecular delivery. Adv Drug Deliv Rev 2006; 58: 996-1008.

[3] Scheuch G, Siekmeier R. Novel approaches to enhance pulmonary delivery of proteins and peptides. J Physiol Pharmacol 2007; 58 (Suppl 5, Pt 2): 615-625.

[4] Siekmeier R, Scheuch G. Systemic treatment by inhalation of macromolecules - Principles, problems, and examples. J Physiol Pharmacol 2008; 59 (Suppl 6), 53-79.

[5] Köhler D, Fleischer W. Medikamente. In: Theorie und Praxis der Inhalationstherapie, D Köhler, W Fleischer (Eds.). Arcis Verlag, München 2000.

[6] Niven RW. Delivery of biotherapeutics by inhalation aerosol. Crit Rev Ther Drug Carrier Syst 1995; 12: 151 231.

[7] Voshaar T. In: Therapie mit Aerosolen. Uni-Med Verlag Bremen 2005, $1^{\text {st }}$ Ed.; 26-28.

[8] Wildhaber J, Kamin W. In: Inhalationstherapie im Kindesund Jugendalter. Uni-Med Verlag Bremen 2008, 1st Ed.; 30-33.

[9] Agu RU, Ugwoke MI, Armand M, Kinget R, Verbeke N. The lung as a route for systemic delivery of therapeutic proteins and peptides. Respir Res 2001; 2: 198-209.

[10] Patton JS, Byron PR. Inhaling medicines: Delivering drugs to the body through the lungs. Nat Rev Drug Discov 2007; 6: 67-74.

[11] Siekmeier R, Scheuch G. Inhaled insulin - Does it become reality? J Physiol Pharmacol 2008; 59 (Suppl 6), 81 113.

[12] Weibel ER. Morphometry of the Human Lung. SpringerVerlag Berlin 1963.

[13] Wolff RK. Safety of inhaled proteins for therapeutic use. J Aerosol Med 1998; 11: 197-219.

[14] Patton JS, Platz RM. Routes of delivery: Case studies. (2) Pulmonary delivery of peptides and proteins for systemic action. Adv Drug Deliv Rev 1992; 8: 179-196.

[15] Valente AXCN, Langner R, Stone HA, Edwards DA: Recent advances in the development of an inhaled insulin product. Biodrugs 2003; 17: 9-17.

[16] Cefalu WTT. Concept, strategies, and feasibility of non-invasive insulin delivery. Diabetes Care 2004; 27: 239-246.

[17] Weibel ER. Morphometry of the human lung: The state of the art after two decades. Bull Eur Physiopathol Respir 1979; 15: 999-1013.

[18] Gänsslen M. Über Inhalation von Insulin. Klin Wochenschr 1925; 4: 71.

[19] Heubner W, de Jongh SE, Laquer E. Über Inhalation von Insulin. Klin Wochenschr 1924; 3: 2342-2343.
[20] Laqueur E, Grevenstuk A. Über die Wirkung intratrachealer Zuführung von Insulin. Klin Wochenschr 1924; 3 : 1273-1274.

[21] Qi Y, Zhao G, Liu D, Shriver Z, Sundaram M, Sengupta S, Venkataraman G, Langer R, Sasisekharan R. Delivery of therapeutic levels of heparin and low-molecularweight heparin through a pulmonary route. Proc Natl Acad Sci USA 2004; 101: 9867-9872.

[22] Scheuch G, Brand P, Meyer T, Herpich C, Müllinger B, Brom J, Weidinger G, Kohlhäufl M, Häussinger K, Spannagl M, Schramm W, Siekmeier R. Anticoagulative effects of the inhaled low molecular weight heparin certoparin in healthy subjects. J Physiol Pharmacol 2007; 58 (Suppl 5, Pt 2): 602-614.

[23] Brand P, Beckmann H, Maas-Enriquez M, Meyer T, Müllinger B, Sommerer K, Weber N, Weuthen T, Scheuch G. Peripheral deposition of alpha1-protease inhibitor using commercial inhalation devices. Eur Resp J 2003; 22:263-267.

[24] Byron PR, Patton JS. Drug delivery via the respiratory tract. J Aerosol Med 1994; 7: 49-75.

[25] Frijlink HW, de Boer AH. Nebulization and administration devices. In: Pulmonary Drug Delivery. Basics, Applications and Opportunities for Small Molecules and Biopharmaceutics. Bechtold-Peters K, Luessen H (Eds.). Editio Cantor Verlag, Aulendorf 2007; 124-153.

[26] Brand P, Häußermann S, Müllinger B, Fischer A, Wachall $\mathrm{B}$, Stegemann J. Intra-pulmonal deposition of two different tobramycin formulations. Journal of Cystic Fibrosis 4 (2005) S34-S58.

[27] McNamara PS, McCormack P, McDonald AJ, Heaf L, Southern KW. Open adherence monitoring using routine data download from an adaptive aerosol delivery nebulizer in children with cystic fibrosis. J Cyst Fibros 2009; 8: 258-263.

[28] Dopfer R, Brand P, Müllinger B, Hunger T, Häussermann S, Meyer T, Scheuch G, Siekmeier R. Inhalation of tobramycin in patients with cystic fibrosis: comparison of two methods. J Physiol Pharmacol 2007; 58 (Suppl. 5) 141-154.

[29] Ramsey BW, Pepe MS, Quan JM, Otto KL, Montgomery $\mathrm{AB}$, Williams-Warren J, Vasiljev KM, Borowitz D, Bowman CM, Marshall BC, Marshall S, Smith AL. Intermittent administration of inhaled tobramycin in patients with cystic fibrosis. Cystic Fibrosis Inhaled Tobramycin Study Group. N Engl J Med 1999; 340: 23-30.

[30] Köhler E, Sollich V, Schuster-Wonka R, Jorch G. Lung deposition after electronically breath-controlled inhalation and manually triggered conventional inhalation in cystic fibrosis patients. J Aerosol Med 2005; 18: 386-395.

[31] Fischer A, Schiefer T. Patient satisfaction with individualized controlled breathing. FORM, 28th European CF Conference; Crete, Greece; 22 $2^{\text {nd }}-25^{\text {th }}$ June 2005 (Poster).

Address for correspondence:

PD Dr. R. Siekmeier

Bundesinstitut für Arzneimittel und Medizinprodukte (BfArM)

Kurt-Georg-Kiesinger-Allee 3

53119 Bonn

Germany

E-mail: R.siekmeier@bfarm.de 